\title{
Multicriteria-based decision making models for computer integrated enterprise
}

\author{
Lj. B. Vlacic \\ Senior Lecturer \\ Faculty of Science and Technology, Griffith University, \\ Brisbane, Qld, 4111, Australia, phone: +61 73875 5024, \\ fax: +6173875 5384,e-mail: L.Vlacic@me.gu.edu.au
}

\begin{abstract}
This paper deals with the need for and the applicability of multicriteria-based decision making techniques in computer integrated enterprise/manufacturing environments. Interim literature survey results are also presented.
\end{abstract}

\section{Keywords}

Computer-integrated enterprises, computer-integrated manufacturing, multicriteria-based decision making; economic implementation models.

\section{INTRODUCTION}

Today's industrial environment and its ever increasing requirements for productivity, high quality, flexibility and low operating costs for industrial manufacturing plants demand the development of new techniques across all operational levels of a manufacturing system. The integration of the information and control system for a manufacturing enterprise requires the co-ordination of a vast number of factors in the face of continual, unpredictable changes in the factory's internal and external environment.

The existence of a large number of unpredictable changes in the factory's operation, which occur randomly in time and location, demands the use of control strategies in their broadest sense and the integration of all aspects of the plant's operations. This means that all manufacturing and human-based tasks must be factored into the design and operation of the control and decision support systems which will operate the plant in order to provide the highest exploitation of the installed production capacity, increased productivity, reduced 
manufacturing time, and greater flexibility of operation. These requirements are so varied, numerous and often contradictory. In order to meet all of them, multicriteria-based decisionmaking techniques should be used.

This paper is an interim report on latest developments, in applying these techniques across a range of issues of relevance to computer integrated enterprise, and is organised as follows. Section 2 deals with investment related decision-making while Section 3 deals with an operational decision-making within the framework of computer-integrated enterprise/manufacturing. Section 4 provides a discussion on a multicriteria-based model, developed to be used for decision making during implementation stage of computer integrated enterprise while Section 5 provides an in-brief description of the decision model solving methodology. Finally, in Section 6, conclusions are drawn.

Before approaching the next section, it is important to point out that there are certain differences in the meaning of the terms CIM (Computer Integrated Manufacturing) and CIE (Computer Integrated Enterprise), especially from the viewpoint of industrial automation specialists. Though the analysis of these differences is not the concern of this paper, a distinction will be established following those of the Purdue CIE Reference Architecture (for more details see Williams, 1989) as follows:

- The definition of the term Computer Integrated Manufacturing (CIM) comprises automation of the whole of the manufacturing functions of the enterprise. The computerised automation system (i.e., computer-based control system), in the framework of those functions (process control, production scheduling, sequencing, etc.), acts directly on the plant equipment to accomplish the needed task.

- The definition of the term Computer Integrated Enterprise (CIE) comprises the integration of all aspects of company operations including management related aspects by the computerised automation system. Such computerised automation systems operate as a decision support tool for the individuals carrying out the functions assigned to them (in the framework of corporate management, engineering design, marketing and sales, etc.)

\section{CIE/CIM INVESTMENT RELATED DECISION MAKING}

In the processes of decision making within a manufacturing system, intuition is desirable but not sufficient. This is because each decision causes qualitative and structural changes, not only within the immediate environment, but also within the entire community. Hence, the actual choice is the result of a special process which has a distinctive rationality. Under such circumstances the decision maker needs help and support.

The results of the work of Dreyfus (1984) indicate that a master expert in a decision field is able to treat most of the decision situations as familiar, to recognise them immediately, and to select and implement a decision instantly with great efficiency. However, all situations cannot be meaningfully compared, since they may be measured in totally different units. Thus, a decision maker needs help in the sense that there is a necessity to use the more logical or analytical decision support tools.

In the last decade, the business environment has changed radically, and today many manufacturing plants must compete world-wide for their business and be tuned to the needs of their customers. Consequently, the plant's direction as well as the people's role within the plant should be justified before making major investments in CIE/CIM technology. In their paper, Burstein, et al. (1990) define a procedure for designing and establishing a responsive 
manufacturing plant. Led by both market driven and technology driven success factors, the logical flow of the procedure itself is a multicriteria one. However, probabilistic assessments of alternative courses of action is suggested for use in investment decision making instead of a vector-optimisation based analysis.

Bitton, et al. (1988) in their paper on CIM investment state that the investment analysis should be grounded on all costs and all benefit sources. To determine both the obvious and hidden costs, the GRAI method has been proposed. This method is, in fact, the structured analysis method which is mainly supported by tools of a graphic and procedural nature.

In the paper of Suresh (1991) and Suresh, et al. (1992), an economic evaluation methodology for investment analysis at the flexible automation level has been presented. That methodology is based on the integration of the Integer Goal Programming formulation with the Analytic Hierarchy Process (Saaty, 1980, 1990) to utilise both optimisation and evaluation capabilities. A list of the relevant decision making criteria is provided as well.

The multicriteria-based methodology proposed in the papers of Khorramshahgol, et al. (1988), and Khorramshahgol, et al. (1988) is focused on the Project Evaluation applications. The methodology has been developed by integrating the Integer Goal Programming method and the Delphi method with the Analytic Hierarchy Approach of Saaty (1980).

A general approach to building an effective justification process around a multiattribute decision model has been proposed in the paper of Falkner and Benhajla (1990). Their work contains the most thorough discussion on the CIM investment multicriteria-based decision making. They state, 'In a large percentage of the over 500 papers written on the justification of CIM systems one or more attributes have been discussed as providing concrete benefits which need to be considered in addition to financial measures; however, only a small number of papers have been published which actually present a multi-attribute approach to justification'.

Our literature search, although undertaken 4 years later, confirms the above Falkner-Benhajla statement.

\section{CIE/CIM OPERATIONS RELATED DECISION MAKING}

The requirements for the interconnection of information and control systems throughout a plant in order to fully integrate the co-ordination and control of all operations are covered in detail by the Purdue CIM Reference Model (Williams (ed.), 1989). Moreover, general tasks involved in the overall automation of all manufacturing plants, both continuous and discrete, are also listed in detail by the Purdue Enterprise Reference Architecture (Williams, 1992). Therefore, Williams' approach to CIM/CIE will be followed within the framework of this paper.

In order to present the real manufacturing decision making environment, Figure 1 is reproduced here as a six-level hierarchical control Factory Automation Model (FAM) for manufacturing activities (Williams, (ed.), 1989).

Each level of the computerised automation system has its own specific, unique and complementary role in the realisation of the necessary conditions for achieving an optimal response by the production system to dynamic market changes. The complexity of the decision making procedure changes from one decision making level to another. The effectiveness of the automation of each decision level separately depends on the effectiveness of the automation of other levels. Consequently, a high quality response of such overall production systems to dynamic market and environmental changes becomes achievable through the integration of all company operations. However, the total integration of all company operations is an extremely 


\begin{tabular}{|c|c|c|c|c|}
\hline & HIERARCHY & CONTROL & RESPONSIBILITY & BASIC FUNCTIONS \\
\hline 5 & ENTERPRISE & $\begin{array}{l}\text { CORPORATE } \\
\text { MANAGEMENT }\end{array}$ & $\begin{array}{l}\text { Achieving the mission of the } \\
\text { enterprise and managing the } \\
\text { corporate. }\end{array}$ & $\begin{array}{l}\text { - CORPORATE MANAGEMENT } \\
\text { - FINANCE } \\
\text { - MARKETING \& SALES } \\
- \text { RESEARCH \& DEVELOPMENT }\end{array}$ \\
\hline 4 & FACILITY/PLANT & $\begin{array}{l}\text { PLANNING } \\
\text { PRODUCTION }\end{array}$ & $\begin{array}{l}\text { Implementation of the enterprise } \\
\text { functions, and planning and } \\
\text { scheduling the production. }\end{array}$ & $\begin{array}{ll}\text { - } & \text { PRODUCT DESIGN \& PRODUCTION } \\
- & \text { PRODUCTION MANAGEMENT (Upper Level) } \\
- & \text { PROCUREMENT (Upper LeVel) } \\
- & \text { RESOURCES MANAGEMENT (Upper Level) } \\
- & \text { MAINTENANCE MANAGEMENT (Upper LeVel) }\end{array}$ \\
\hline 3 & SECTION/AREA & $\begin{array}{c}\text { ALLOCATING } \\
\text { AND } \\
\text { SUPERVISING } \\
\text { MATERIALS } \\
\text { AND } \\
\text { RESOURCES }\end{array}$ & $\begin{array}{l}\text { Coordinate the production and } \\
\text { supporting the jobs and obtaining } \\
\text { and allocating resources to the } \\
\text { jobs. }\end{array}$ & $\begin{array}{l}\text { - PRODUCTION MANAGEMENT (Lower Level) } \\
\text { - PROCUREMENT (Lower LeVel) } \\
\text { - RESOURCES MANAGEMENT (Lower Level) } \\
\text { - SHIPPING } \\
\text { - WASTE MATERIAL TREATMENT }\end{array}$ \\
\hline 2 & CELL & $\begin{array}{l}\text { COORDINATE } \\
\text { MULTIPLE } \\
\text { MACHINES } \\
\text { AND } \\
\text { OPERATIONS }\end{array}$ & $\begin{array}{l}\text { Sequencing and supervising the } \\
\text { jobs at the shop floor, and } \\
\text { supervising various supporting } \\
\text { services. }\end{array}$ & - SHOP FLOOR PRODUCTION (Cell Level) \\
\hline 1 & STATION & $\begin{array}{l}\text { COMMAND } \\
\text { MACHINE } \\
\text { SEQUENCES } \\
\text { AND MOTION }\end{array}$ & $\begin{array}{l}\text { Directing and coordinating the } \\
\text { activity of the shop floor } \\
\text { equipments. }\end{array}$ & - SHOP FLOOR PRODUCTION (Station Level) \\
\hline 0 & EQUIPMENT & $\begin{array}{l}\text { ACTIVATE } \\
\text { SEQUENCES } \\
\text { AND MOTION }\end{array}$ & $\begin{array}{l}\text { Realization of commands to the } \\
\text { shop floor equipments. }\end{array}$ & - SHOP FLOOR PRODUCTION (Equipment Level) \\
\hline
\end{tabular}

Figure 1 Factory Automation Model (The Purdue Reference Model for CIM). Source: Williams (ed.) 1989

difficult problem, primarily because of the changing nature of automation across all hierarchical levels.

\section{Lower levels (levels 0, 1 and 2)}

These levels are mainly nonhuman decision making oriented. Processes of decision making at these levels are determined by repetitiveness in decision making, high speed decision making (i.e., short response time), high reliability in decision making, etc. The main objective of automation of all functions from these levels is that of total automatic control. From the aspect of decision systems, it means that it is necessary to automate the process of decision making. This involves the substitution of the decision maker with an appropriate computerised system in such a way that the computer can operate relatively independently of human intervention in carrying out the assigned functions. This kind of automation belongs to the field of decision automation (Wierzbicki, 1988). Level 0 is occupied by plant machinery and equipment; Level 1 - usually by logic, numerical and machine controllers; Level 2 - by cell level control equipment. Although each of these is automatable ${ }^{*}$ the principles of multiple criteria-based decision making will only need to be applied to the cell control level. Only Level 2 has decisions of a complexity requiring vector optimisation techniques.

\footnotetext{
* Automatability requires that the operation of the function and its related physical equipment be expressible in mathematical or computer program terms. If this is not possible, then by definition a human being must supply the information or action which would otherwise be lacking. This is human innovation (Williams, 1991).
} 


\section{Higher levels (levels 3,4, and 5)}

These levels are mostly human decision making oriented. The objective of automation at these levels is not to replace human decision makers, but to support them in their decision making. Tasks from these hierarchical levels usually require human innovation for their implementation and thus cannot be wholly automated. However, they do need computer system support. Therefore, automation of these levels belongs directly to the field of decision analysis and support (Wierzbicki, 1990).

The highest hierarchical level (Level 5) includes those cases involving the greatest potential areas of the application of decision support systems. A generic nature of the corporate management tasks evolves ill-structured decisions and dynamic character of the problems.

A number of modelling techniques such as Petri Nets, Stochastic Petri Nets, General Stochastic Petri Nets, Queuing Networks, Marker Chains, Perturbation Analysis, Computer Simulation, etc. have been used to model decision making architectures across all hierarchical levels of CIE/CIM systems (see, for example, Al-Jaar and Desrochers (1990, 1992), Suri (1985), Ho (1987), Stecke and Golberg (1985)

These approaches, however, are not well suited primarily because they are single-objective oriented approaches. This work addresses only those references which are multiple-objective oriented.

In the study of Lee and Jung (1989), the Goal Programming Model has been discussed over other models when solving the production planning problems for flexible manufacturing systems.

The paper of Ro and Kim (1990) is concerned with the operational control problems in flexible manufacturing systems. A simulation model using SLAM II and FORTRAN has been developed in order to analyse the influence of six performance measures. However, the applied process selection approach is, in fact, a sum of single criteria-based rules and, consequently, this attempt does not provide its user with a multicriteria based decision making procedure.

An Integer Programming technique has been applied in multi-objective minimisation of the operation-allocation problem in a flexible manufacturing system in the paper of Taboun and Ulger (1992). Computational difficulties associated with large size problems still exist.

Three multicriteria-based decision making techniques (Weighting Technique, ZiontsWallenius and Compromise Programming Technique) have been applied for the calculation of the nondominant solution set, in the paper of Mitwasi, Connolly and Duckstein (1989). It is reported that '.. the multicriteria consideration is vastly superior to traditional methods which offer a best solution in terms of a single objective.'

The papers of Chryssolouris, et al. $(1986,1991)$ present the MADEMA concept - a multicriteria decision making procedure for manufacturing systems. The concept is based on a hierarchical structure of the manufacturing system and utilises decision theory in tandem with randomised search networks. The procedure has also been experimentally implemented on a software system written in LISP.

A reference point optimisation technique (Wierzbicki, 1982) has been applied in real-time multiobjective co-operation control of multi-machine workstations (Level 2 of the manufacturing hierarchy) in the paper of Vlacic and Nof (1994). The algorithm has been successfully tested. Further analysis aims to solve a negotiation issue among intelligent machines.

Finally, the paper of Ray and Sahu (1990) calls for application of the utility functions concept in productivity/performance analysis. The paper states that '.. the application of multicriteria 
decision making procedures provides the relationship of productivity with other performance measures.

\section{CIE/CIM IMPLEMENTATION DECISION MODEL}

After the CIE/CIM system has been installed it enters into the operation stage of its life cycle. There are a number of published reports on analysis of effects of computerisation of industrial plants, prepared on the basis of experience acquired during early implementation of CIE/CIM in the workplace. However, all reports are a class of 'questionnaire-based' analysis.

According to our reference search to date, only one report has been published that attempts to provide a multicriteria-based analysis of effects of CIE/CIM operations in real industries. The report is by Nakamura (1994) which analyses the experiences of six Japanese production plants that have recently implemented CIE/CIM. The developed multicriteria model consists of 20 criteria structured across two hierarchical levels with a decision model solving methodology, founded on an aggregation procedure for hierarchically grouped decision criteria.

The developed decision model is hierarchically structured and covers the following criteria (Table 1):

It is a known fact in decision theory that models often have hierarchical structure and that the criteria of a lower level must be grouped and aggregated into a criterion of the upper level. The theoretical foundations of such aggregation require rather complicated testing of various

Table 1 The decision model

\begin{tabular}{ll}
\hline Main criteria & Basis for evaluation of the main criteria \\
\hline Economic impact & Profitability \\
& Operational risk \\
Strategic impact & Net present value \\
& Customer satisfaction (service) \\
& Reduced lead time \\
Improved quality of products \\
Social impact & Larger portion of market share \\
& Labour loading \\
& Labour productivity \\
& Training requirement \\
Operational impact & Motivation \\
& Delivery schedule performance \\
& Productivity \\
& Inventory \\
& Maintainability \\
& Flexibility \\
& Quality control \\
& Decision making \\
& Efficiency of integration \\
& Organisational structure \\
\hline
\end{tabular}


independent assumptions, hence most applied examples of such aggregation are based on heuristics. We apply here an aggregation procedure for hierarchically grouped decision making criteria developed by Vlacic, Matic and Wierzbicki (1986).

First level criteria need to be subdivided into lower order criteria. In our case, all second order performance measures are measurable, and consequently, can be accepted as decision making criteria. As can be seen from Table 1, the upper level criteria express composite evaluations of lower level criteria. For example, the criterion 'Economic impact' expresses the composite evaluation of lower level criteria, namely profitability, operational risk and net present value.

The important part of our model is that most of the criteria regardless of the hierarchical level they belong to, can only be subjectively assessed, while very few of them can be analytically modelled and thus expressed quantitatively.

However, applied decision model solving methodology can assist us in aggregating the lower level criteria (which are of either a qualitative or quantitative nature) into the composite upper level criteria which can further assist in aggregating all subjective assessments of upper level criteria into an overall assessment. Details on how to apply and evaluate criteria for the above decision model (Table 1) can be found in the report by Nakamura (1994).

\section{A DECISION MODEL SOLVING METHODOLOGY}

The core of the multicriteria decision making algorithm is a choice of a utility or value function of a decision maker or of a team of them. There are many known forms of utility or value functions, see for details Keeney and Raiffa $(1976,1982)$. A utility or value function which is consistent with engineering applications was proposed by Wierzbicki (1982) as a so called order-consistent achievement function that is used to scalarize achievements on multiple objectives and depends parametrically on contextual information on the attainable ranges of values for these objectives as well as on the placement of so called reference levels - which might be interpreted as aspiration or reservation levels, or both - in these ranges. This contextual information is usually available and important in engineering applications.

A corresponding order-consistent achievement function has been defined as follows:

$u_{i}\left(y_{i}, \bar{y}_{i}^{\prime}, \bar{y}_{i}^{\prime \prime}\right)= \begin{cases}b\left(\left(y_{i}-y_{i, \min }\right) /\left(\bar{y}_{i}^{\prime}-y_{i, \min }\right)-1\right), & \text { if } y_{i, \min } \leq y_{i} \leq \bar{y}_{i}^{\prime} \\ \left(y_{i}-\bar{y}_{i}^{\prime}\right) /\left(\bar{y}_{i}^{\prime \prime}-\bar{y}_{i}^{\prime}\right), & \text { if } \bar{y}_{i}^{\prime}\left\langle y_{i}\left(\bar{y}_{i}^{\prime \prime}\right.\right. \\ a\left(y_{i}-\bar{y}_{i}^{\prime \prime}\right) /\left(y_{i, \min }-\bar{y}_{i}^{\prime \prime}\right)+1, & \text { if } \bar{y}_{i}^{\prime \prime} \leq y_{i} \leq y_{i, \max }\end{cases}$

$u(y, \bar{y})=\left\{\min _{1 \leq i \leq p} u_{i}\left(y_{i}, \bar{y}_{i}\right)+(c / p) \sum_{i=1}^{p} \min u_{i}\left(y_{i}, \bar{y}_{i}\right)\right\} /(1+c)$

where $0 \leq c<p-$ a weighting coefficient

$\bar{y}^{\prime}=\left(\bar{y}_{1}^{\prime}, \ldots \bar{y}_{i}^{\prime}, \ldots \bar{y}_{p}^{\prime}\right)-$ an aspiration point

$\bar{y}^{\prime \prime}=\left(\bar{y}_{1}^{\prime \prime}, \ldots \bar{y}_{i}^{\prime \prime}, \ldots \bar{y}_{p}^{\prime \prime}\right)-$ a reseration point 
The above achievement function has been extensively used in carrying out CIE/CIM implementation decision analysis. For more details and obtained results, please see the report prepared by Nakamura (1994).

\section{CONCLUSIONS}

In the complex decision making environment, such as in computer integrated enterprise, there are a number of objectives which are in conflict. This has resulted in increased importance of the applicability of multicriteria-based decision making techniques. In spite of this need, this interim survey shows that there have been very few attempts to adopt such an approach.

The developed decision model is to be used to measure the economic, strategic, social and organisational impacts of the CIE/CIM implementation on the company and to help industry decision makers to evaluate to what extent the company's vision became reality. The model has already been successfully used in analysing survey results obtained from CIE enterprises in Japan.

\section{ACKNOWLEDGMENTS}

A part of the cost of this research has been granted by the 1994 Monbusho International Collaborative Research Programme Grant of Japan and Bilateral Science and Technology Collaboration Program DIST Australia 93/3930. The author is thankful.

A special thanks goes to A.P. Wierzbicki for his valuable comments while discussing with us a question on a decision model solving methodology.

\section{REFERENCES}

Al-Jaar, R.Y. and Desrochers, A.A. (1990) A Methodology for Evaluating Decision Making Architectures for Automated Manufacturing Systems. Proceedings 11th IFAC Congress, Tallinn, pp. 321-326

Al-Jaar, R.Y. and Desrochers, A.A. (1992) Performance Evaluation of Real-time DecisionMaking Architectures for Computer-Integrated Manufacturing Systems. Robotics and Computer-Integrated Manufacturing, Vol. 9, No. 3, pp. 255-277.

Bitton, M. and Doumeingts, G. (1988) Economic Evaluation for C.I.M. Systems: A Global Approach Using the GRAI Method. Information Technology for Organisational Systems, pp. 184-189.

Burstein, M.C. and Graham, P. (1990) Strategic Justification of Plant-Level Investments. Manufacturing Review, Vol. 3, No. 3, pp. 171-177.

Chryssolouris, G., Pierce, J. and Dicke, K. (1991) An Approach for Allocating Manufacturing Resources to Production Tasks. Journal of Manufacturing Systems, Vol. 10, No. 5, pp. $368-382$.

Chryssolouris, G., Wright, K. and Soo, P. (1986) A Rule-based System for Selection of Performance Criteria in Manufacturing. Proceedings, 14th North American Manufacturing Research Conference, Minneapolis, Minnesota, pp.543-551. 
Chryssolouris, G., Dicke, R. and Lee, M. (1991) An Approach to Short Interval Scheduling for Discrete Parts Manufacturing. Int. J. Computer Integrated Manufacturing, Vol. 4., No. 3, pp. 157-168.

Dreyfus, S.E. (1984) Beyond Rationality, in Plural Rationality and Interactive Decision Processes (eds Graver, Thompson and Wierzbicki), Springer-Verlag.

Enkawa, T. (1992) CIM: The state of the art and onwards to IMS. Journal of Japan Industry Management Association (in Japanese), Vol. 2, No. 1.

Falkner, C.H. and Benhajla, S. (1990) Multi-attribute Decision Models in the Justification of CIM Systems. The Engineering Economist, Vol. 35, No. 2, pp 91-114.

Hitomi, K. (1989) CIM Gairon. Omu-sha (in Japanese), pp 106-109.

Ho, Y.C. (1987) Performance Evaluation and Perturbation Analysis of Discrete Event Dynamic Systems. IEEE Trans. Automatic Control AC-32; pp. 563-572.

Keeney, R.L. and Raiffa, H. (1976) Decisions with multiple objectives: preferences and value trade-offs. Wiley, NY.

Keeney, R.L. and Raiffa, H. (1982) Multiattribute Utility Theory. J. Wiley \& Sons.

Khorramshahgol, R. and Steiner, H.M. (1988) Resource Analysis in Project Evaluation: A Multicriteria Approach. Journal of Operational Research Societies, Vol. 39, No. 9, pp. 795-803.

Khorramshahgol, R., Azani, H. and Gousty, Y. (1988) An Integrated Approach to Project Evaluation and Selection. IEEE Transactions on Engineering Management, Vol. 35, No. 4, pp. 265-270.

Lee, S.M. and Jung, H-J (1989) A Multi-objective Production Planning Model in a Flexible Manufacturing Environment. International Journal of Production Research, Vol. 27, No. 11, pp. 1981-1992.

Mitwasi, M., Connolly, A.M. and Duckstein, L. (1989) Applying Multicriteria Decision Making Techniques for Planning Machining Operations. Applied Mathematics and Computation, Vol. 29, pp. 197-218.

Nakamura, T (1994) Non-Technical Performance Measures of Computer Integrated Enterprise: A Multicriteria Model. MSc Thesis, The University of ElectroCommunications, Japan.

Ray, P. and Sahu, S. (1990) Productivity Measurement Through Multi-criteria Decision Making. Engineering Costs and Production Economics, 20, pp. 151-163.

Ro, I.K. and Kim, J.I. (1990) Multi-criteria Operational Control Rules in Flexible Manufacturing Systems (FMS). International Journal of Production Research, Vol. 28, No. 1, pp. 47-63.

Saaty, T.L. (1980) The Analytic Hierarchy Process. McGraw-Hill, NY.

Saaty, T.L. (1990) How to make a decision: The Analytic Hierarchy Process. European Journal of Operational Research, 48, pp. 9-26.

Stecke, K.E., and Golberg, J.J. (1985) The Optimality of unbalancing both workloads and machine group sizes in closed queueing networks of multiserver queues. Operations Research, 33, pp. 882-910.

Suresh, N. (1991) An Extended Multi-objective Replacement Model for Flexible Automation Investments. International Journal of Production Research, Vol. 29, No. 9, pp. 18231844. 
Suresh, N.C. and Kaparthi, S. (1992) Flexible Automation Investments: A Synthesis of Two Multi-objective Modelling Approaches. Computers in Engineering, Vol. 22, No. 3, pp. 257-272.

Suri, R. (1985) An Overview of Evaluative Models for Flexible Manufacturing Systems. Ann. Operations, Res 3.

Suri, R. et al. (1985) Modelling flexible manufacturing systems using mean-value analysis. Journal of Manufacturing Systems, 3, pp. 27-38.

Taboun, S.M. and Ulger, T. (1992) Multi-objective Modelling of Operation-allocation Problem in Flexible Manufacturing Systems. Computers and Industrial Engineering, Vol. 23, Nos 1-4, pp. 295-299.

Vlacic, Lj (1989) Decision support systems in the design of process control systems. Information and Decision Technologies, Vol. 15, pp. 179-191.

Vlacic, Lj., and Nof, S. (1994) Real-Time Multiobjective Co-operation Control of MultiMachine Workstations, in: Proceedings of IFAC Workshop on Intelligent Manufacturing Systems, June, 13-15, Vienna.

Vlacic, Lj., Matic, B. and Wierzbicki, A.P. (1986) Aggregation Procedures for Hierarchically Grouped Decision Attributes with Application to Control System Performance Evaluation, in Recent Advances and Historical Development of Vector Optimisation (eds Jahn and Krabs) Springer-Verlag, pp. 285-311.

Wierzbicki, A.P. (1982) A Mathematical Basis for Satisfying Decision Making. Mathematical Modelling, 3, 391-405.

Williams, T.J. (1991) The Purdue Enterprise Reference Architecture. Research Report 154, Purdue University.

Williams, T.J. (ed.) (1989) A Reference Model for Computer Integrated Manufacturing (CIM): A Description from the Viewpoint of Industrial Automation. Instrument Society of America.

\section{BIOGRAPHY}

Before joining Griffith University in 1991, Ljubisa Vlacic, SMIEAust CPEng MIEEE, was R\&D control engineer in industrial research organisations UNIS-Institute and ENERGOINVEST-IRCA dealing with design and development of range of commercial products for control applications in process, manufacturing, food and aviation industries. He simultaneously worked at the University of Sarajevo and its Faculty of Electrical Engineering.

He has authored or co-authored around 60 conference and journal articles, book-chapters and research monograph. His current research interests include intelligent control systems, enterprise integration, multiattribute decision analysis and real-time decision support systems.

Dr Vlacic is a chartered professional engineer, a Senior Member of the Institute of Engineers Australia (IEAust) and a member of the IEEE. 